\title{
Relationship Between Achievement Goals, Meta-Cognition And Academic Success In Pakistan
}

\author{
Muhammad Sarwar, University of Sargodha, Pakistan \\ Muhammad Imran Yousuf, Pir Mehr Ali Shah Arid Agriculture University, Pakistan \\ Shafqat Hussain, GC University, Faisalabad, Pakistan \\ Shumaila Noreen, Dar-E-arqum School, Pakistan
}

\begin{abstract}
The research was the replication of the study done by Coutinho (2006) and it aimed at finding the relationship between achievement goals, meta-cognition and academic success. Achievement goals were further divided into two types: mastery and performance. The participants were 119 students enrolled in M. A. Education, Department of Education at the University of Sargodha. The questionnaire used in the original study, along with Urdu translation, was administered to the participants. The questionnaire consisted of three sections measuring mastery goals, performance goals, and meta-cognition, respectively. The academic achievement record was taken from the Office of Department of Education. Academic achievement was taken as marked and obtained at the Matric, Intermediate, Bachelors, and M.A. levels. It was concluded there is no significant correlation between mastery goals and academic achievement. Similarly, there was no significant correlation between performance goals and academic achievement at Matric, Intermediate and Bachelor levels. However, negative correlation was observed between performance goals and achievement at the masters level. The researchers found no significant relationship between metacognition and academic achievement at all levels and there were no significant gender differences in mastery goals, performance goals and meta-cognition.
\end{abstract}

Keywords: Academic achievement, meta-cognition, academic success, mastery goals, performance goals

\section{INTRODUCTION}

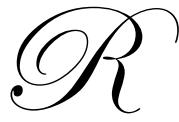

esearchers in the field of educational psychology have investigated a number of variables in their relationship to academic achievement. Two variables that have been of particular interest to researchers are achievement goals and metacognition. The present study is a replication of the study by Coutinho (2006) and it seeks to examine achievement goals and metacognition in relation to academic achievement in Pakistani background. A goal is an outcome or attainment for which an individual is striving to accomplish (Locke \& Latham, 1990). There are two main types of achievement goals: mastery and performance (Dweck and Leggett, 1988). The mastery goal focuses on the task at hand and is not worried about others in class.

The students may focus on getting good test scores and grades, or they may be more concerned with winning and beating other students (Wolter \& Printrich 1996). A student whose goal is outperforming others may do things to look smart, such as reading more books, to get the highest marks. They may be labeled as ego-involved learners. The third variable involved in this study is meta-cognition, which is thinking about thinking. Awareness of one's own thinking process is necessary for talking about thinking. Once people are aware of thinking as a process, they can reflect on how they are thinking and discover effective ways of thinking and learning. All children are capable of thinking and reasoning. Children in grade one, and even younger, can learn to notice their own minds at work. Awareness of the thinking process is very important for the development of abilities to think and learn. 


\section{OBJECTIVES}

1. To find the relationship of mastery goals and academic performance

2. To find the relationship of performance goals and academic performance

3. To find the relationship of meta-cognition and academic performance

4. To investigate the gender differences in mastery goals, performance goals and meta-cognition

\section{RESEARCH HYPOTHESES}

1. There will be no significant correlation between mastery goals and academic performance.

2. There will be no significant correlation between performance goals and academic performance.

3. There will be no significant correlation between meta-cognition and academic performance.

4. There will be no significant gender difference in mastery goals, performance goals and meta-cognition.

\section{SIGNIFICANCE OF THE STUDY}

Academic achievement is a very complex variable and it is affected by many variables. Research indicates that the impact of achievement goals and meta-cognition on academic achievement may help the stakeholders to improve the quality and outcome of education. Therefore, the results of the study may help us to have a clearer understanding of the academic performance. The study, in spite of being a replication, is different from the original study as it has been conducted in university settings with M. A. students. Another difference is that of the educational system. The original study was conducted in the US and this study was done in non-western culture, so the findings will help us compare the differences in students in two educational settings.

\section{SAMPLE}

The sample of the study consisted of 119 students in the Department of Education who were enrolled in the M. A. Education sessions 2005-2007 and 2006-2008. Semester-wise, the breakup was: 36 students from the $1^{\text {st }}$ semester, 42 from the $3^{\text {rd }}$ semester, and 41 from the $4^{\text {th }}$ semester. Gender-wise, the breakup consisted of 13 males and 106 females.

\section{TOOLS}

The questionnaire used in the study was developed by Coutinho (2007) and the researchers used it, along with the Urdu translation, to ensure complete understanding and comprehension to increase reliability, as well as the validity of the tool. The questionnaire comprised of three sections: The first comprised of 12 items assessing Mastery Goals (MG), the second contained five items assessing Performance Goals (PG), and the third was the 50item Meta-cognitive Awareness Inventory (MAI). Participants responded to each item on a 5-point scale ranging from strongly disagree (1) to strongly agree (5). Marks, which they achieved in Matric, Intermediate, Bachelors and M. A. levels, were taken as the students' achievement. Record for academic achievement was taken from the office of the Department of Education at the University of Sargodha.

\section{DATA COLLECTION}

The M.A. Education students were briefed about the study and were requested to participate. The respondents were asked to complete the questionnaire, marking their responses using a 5-point Likert scale ranging from strongly agree to strongly disagree. The questionnaire also requested some demographic information, such as name, semester, roll number, etc., which was used to get data about the academic achievement records in the Department of Education office. 


\section{DATA ANALYSIS}

Data were analyzed by SPSS (statistical package for social sciences) to correlate mastery goals, performance goals and meta-cognition with academic achievement at different levels; i.e. Matric, Intermediate, Bachelors and Masters.

\section{RESULTS}

The first hypothesis was, "There will be no significant correlation between mastery goals and academic performance." This hypothesis was separately investigated for marks obtained in the Matric, Intermediate, Bachelors, and Master levels

Table 1: Correlations between Mastery Goals (MG) and Academic Achievement (AA)

\begin{tabular}{|c|l|c|c|c|}
\hline Sr. No. & \multicolumn{1}{|c|}{ Variables } & Pearson Correlation & Sig. & N \\
\hline 1 & Mastery goals and SSC Marks & .039 & .675 & 119 \\
\hline 2 & Mastery goals and Inter Marks & -.087 & .346 & 119 \\
\hline 3 & Mastery goals and Bachelors Marks & -.059 & .523 & 119 \\
\hline 4 & Mastery goals and MA Marks & .015 & .923 & 41 \\
\hline
\end{tabular}

Table 1 reflects that the significant level of all four correlations is more than .05 , so the null hypothesis was not rejected. Therefore, there is no correlation between mastery goals (MG) and academic achievement (AA) at any level; i.e., Matric, Intermediate, Bachelors, and M. A.

The second hypothesis was, "There will be no significant correlation between performance goals and academic performance."

This hypothesis was also separately investigated for achievements in the Matric, Intermediate, Bachelors, and Master levels.

Table 2: Correlations of Performance Goals (PG) with Academic Achievement (AA)

\begin{tabular}{|c|l|c|c|c|}
\hline Sr. No. & \multicolumn{1}{|c|}{ Variables } & Pearson Correlation & Sig. & N \\
\hline 1 & Performance goals and Metric Marks & -.116 & .208 & 119 \\
\hline 2 & Performance goals and Intermediate Marks & -.059 & .521 & 119 \\
\hline 3 & Performance goals and Bachelors Marks & .107 & .248 & 119 \\
\hline 4 & Performance goals and M. A. Marks & -.357 & .022 & 41 \\
\hline
\end{tabular}

Table 2 shows that the null hypothesis was not rejected in the case of matriculation, intermediate and bachelor level marks. However, the null hypothesis was rejected in the case of M.A. marks and it shows that there is a significant correlation between Performance Goals (PG) and MA Education Marks; but the correlation is negative, which is contrary to the original study.

The third hypothesis was, "There will be no correlation between meta-cognition and academic performance."

Table 3: Correlations of Meta-cognition and Academic Achievement (AA)

\begin{tabular}{|c|l|c|c|c|}
\hline Sr. & \multicolumn{1}{|c|}{ Variables } & Pearson Correlation & Sig. & N \\
\hline 1 & Meta-cognition and Metric Marks & -.059 & .522 & 119 \\
\hline 2 & Meta-cognition and Intermediate Marks & -.083 & .371 & 119 \\
\hline 3 & Meta-cognition and Bachelors Marks & -.070 & .449 & 119 \\
\hline 4 & Meta-cognition and M. A. Marks & -.257 & .110 & 40 \\
\hline
\end{tabular}


Table 3 shows that the null hypothesis, "There will be no significant correlation between meta-cognition and academic achievement" has been rejected. The table also shows that there is a negative, but non-significant, relationship between meta-cognition and academic achievement (AA) - Matric, Intermediate, Bachelors and Masters level marks.

The fourth hypothesis is, "There will be no significant gender difference in Mastery goals, Performance Goals and Meta-cognition."

Table 4: Gender Differences In Mastery goals, Performance Goals and Meta-cognition,

\begin{tabular}{|c|c|c|c|c|c|c|c|c|}
\hline Sr. & Variables & $\mathbf{N}$ & Mean & Std. Dev. & Std. Error Mean & $\mathbf{t}$ & Df & Sig. \\
\hline \multirow[t]{2}{*}{1} & \multirow{2}{*}{$\begin{array}{l}\text { Mastery goals Females } \\
\text { Males }\end{array}$} & 106 & 47.08 & 4.56 & .44 & \multirow[t]{2}{*}{1.073} & \multirow[t]{2}{*}{117} & \multirow[t]{2}{*}{.285} \\
\hline & & 13 & 46.38 & 3.93 & 1.09 & & & \\
\hline \multirow[t]{2}{*}{2} & \multirow{2}{*}{$\begin{array}{l}\text { Performance goals Females } \\
\text { Males }\end{array}$} & 106 & 19.08 & 3.14 & .30 & \multirow[t]{2}{*}{.648} & \multirow[t]{2}{*}{117} & \multirow[t]{2}{*}{.518} \\
\hline & & 13 & 18.46 & 3.89 & 1.08 & & & \\
\hline \multirow[t]{2}{*}{3} & \multirow{2}{*}{$\begin{array}{l}\text { Meta-cognition Females } \\
\text { Males }\end{array}$} & 106 & 198.07 & 18.29 & 1.78 & \multirow[t]{2}{*}{1.318} & \multirow[t]{2}{*}{117} & \multirow[t]{2}{*}{.190} \\
\hline & & 13 & 191 & 17.74 & 4.92 & & & \\
\hline
\end{tabular}

Table 4 shows that the null hypothesis, "There will be no significant gender difference in Mastery goals, Performance Goals and Meta-cognition", has not been rejected. Therefore, there are no gender differences in mastery goals, performance goals and meta-cognition.

\section{FINDINGS AND CONCLUSIONS}

Four variables of the study were mastery goals, performance goals, meta-cognition, and academic achievement.

1. There was no correlation between the following: mastery goals and academic achievement, performance goals and academic achievement (Matric, Intermediate, and Bachelors).

2. There was negative correlation between the masters achievement and performance goals.

3. There is a negative, but non-significant, relationship between meta-cognition and academic achievement.

4. No significant gender differences in mastery goals, performance goals, and meta-cognition have been found. This finding is in line with the findings of Ergul (2004).

\section{DISCUSSION}

The present study entitled Correlation Between Achievement Goals, Meta-cognition and Academic Success is the replication of the study done by Coutinho (2006) and aimed at finding the relationship among these variables in Pakistani backgrounds. Findings of this study are somewhat inconsistent with previous researches. No correlation between mastery goals and academic achievement was found. These findings are strange and are not in line with the findings of Coutinho (2006) and Bouffard, Boisvert, Vezeau, and Larouche, (1995); but it can be the case that academic success does not necessarily measure learning, and it can be measuring only rote memorization.

Performance goals were found to have negative correlation with academic achievement at the Masters level, whereas no significant correlation was found between performance goals and achievement (Matric, Intermediate and Bachelors). The researchers found no significant relationship between meta-cognition and academic achievement at all levels. This finding is in line with the findings of some of the previous researches (Mousoulides \& Philippou, 2005; Ergul, 2004)), but these findings are against the findings of some of the researches (Pintrich \& De Groot, 1990; Isaacon \& Fujita, 2006; Coutinho, 2006). 
The reason for this difference in findings may be because the studies that found significant correlation between meta-cognition and academic achievement were conducted in developed countries; i.e.; U. S. A. that have a highly developed educational system, while the studies that found a negative relationship between meta-cognition and academic achievement; i.e., study by Mousoulides \& Philippou (2005), were done in Cyprus. Another study done by Ergul (2004) was conducted in Turkey and it found no relationship between academic achievement and meta-cognition. So, a very important factor in the relationship between meta-cognition and academic achievement can be the difference in the education system. The examination system also plays a very vital role, whether it promotes rote learning or actual mastery of the content to be learned.

Basically, researchers found that more research with these variables and different students is needed to learn how these variables are affecting students' learning and achievement in Pakistani backgrounds and how these effects are different from those found in other cultures.

\section{AUTHOR INFORMATION}

Sarwar, Muhammad is working as Assistant Professor in Department of Education, University of Sargodha, Pakistan. He did his M.Phil. in Education at Allama Iqbal Open University, Pakistan and Ph.D. in Education from University Institute of Education and Research, UAAR, Pakistan.

Yousuf, M. Imran is working as Assistant Professor in Division of Continuing Education, Pir Mehr Ali Shah Arid Agriculture University, Rawalpindi, Pakistan. He did his M.Phil. in Education at Allama Iqbal Open University, Pakistan and Ph.D. in Education from University Institute of Education and Research, UAAR, Pakistan.

Hussain, Shafqat is working as Assistant Professor in Department of Educaion, Government College University, Faisalabad, Pakistan. He did his M.Phil. in Education at Allama Iqbal Open University, Pakistan and Ph.D. in Education at University Institute of Education and Research, UAAR, Pakistan.

Noreen, Shumaila is working as senior teacher at Dar-E-Arqum School System, Sargodha, Pakistan. She did her M.A. in Teacher Education at University of Sargodha.

\section{REFERENCES}

1. Bouffard, T. , Boisvert, J., Vezeau, C., \& Larouche, C. (1995). The impact of goal orientation on selfregulation and performance among college students. British Journal of Educational Psychology, 65(3), 317-329. Retrieved December 8, 2007, from http://epm.sagepub.com/cgi/content/abstract/64/2/290

2. Coutinho, A. S. (2006). The Relationship between the Need for Cognition, Metacognition, and Intellectual Task Performance. Educational Research and Reviews, 1 (5), 162-164. Retrieved December 7, 2007, from http://www.academicjournals.org/err/PDF/Pdf2006/Aug/Coutinho.pdf

3. Dunlosky, J., \& Hertzog, C. (1998). Training programs to improve learning in later adulthood: Helping older adults educate themselves. In D. J. Hacker, J. Dunlosky, and A. C. Graesser (Eds.), Metacognition in Educational Theory and Practice. JN: Erlbaum.

4. Dweck, C. S. (1986). Motivational process affecting learning. American Psychologist, 41,1040-1047.

5. Ergul, H. Dr. (2004). Relationship between student characteristics and academic achievement in distance education and application on students of Anadolu University. Turkish Online Journal of Distance Education, 5 (2). Retrieved December 7, 2007, from http://tojde.anadolu.edu.tr/tojde14/articles/ergul.htm

6. Isaacson, M. R., \& Fujita, F. (2006). Metacognitive knowledge monitoring and self-regulated learning: Academic success and reflections on learning. Journal of the Scholarship of Teaching and Learning, 6(1), 39 - 55. Retrieved November 16, 2007, from http://www.iupui.edu/ josotl/VOL 6/NO 1/v6n1Isaacson.pdf

7. Locke, E. A., \& Latham, G. P. (1990). A theory of goals setting and task performance. Englewood Cliffs, NJ: Prentice-Hall. 
8. Mousoulides, N., \& Philippou, G. (2005). Students' motivational beliefs, self-regulation strategies and mathematics achievement. In H. L. Chick, \& J. L. Vincent (Eds.), 29th Conference of the International Group for the Psychology of Mathematics Education: Vol. 3, pp. 321-328. Melbourne: PME. Retrieved December 7, 2007, from http://www.emis.de/proceedings/PME29/PME29 RRPapers/PME29Vol3MousoulidesPhilippou.pdf

9. Pintrich, P. R., \& De Groot, E. V. (1990). Motivational and Self-Regulated Learning Components of Classroom Academic Performance. Journal of Educational Psychology, 82(1), 33-40. Retrieved December 7, 2007, from http://www.stanford.edu/dept/SUSE/projects/ireport/articles/self-regulation/selfregulated\%20learning-motivation.pdf

10. Wolters, C. A., Yu, S., \& Pintrich, P. R (1996). The relation between goal orientation and students' motivational beliefs and self-regulated learning. Learning and individual differences, 11, 281-299.

\section{NOTES}

